\title{
Cartas en la antigüedad. Desde la Grecia clásica hasta san Jerónimo
}

\author{
Sergio Pérez Cortés
}

a no recuerdo cuándo recibí mi última carta íntima y personal. Desde Iuego, estoy inmerso como todos en una multitud de cartas cotidianas, pero en su inmensa mayoría se trata de documentos comerciales o profesionales, mientras mis cuestiones amistosas o afectivas son confiadas a esos mensajes sin cuerpo que transmiten el teléfono y los medios electrónicos. La carta personal llena de afecto, pensamicntos y confidencias se ha vuelto, para mí, una rareza.

Y sin embargo, durante mucho tiempo la carta en papiro o en papel fue el medio privilegiado para aproximar a los distantes, por eso los antiguos decian de ella que era un diálogo partido a la mitad. La carta restablecía la presencia y la voz viva del ausente: "mientras os escribo esta carta me parece que os estoy viendo". "Ella podía recibir, en consecuencia, el mismo afecto: "ahora converso con vuestra carta, la abrazo y ella conversa conmigo, porque aquí sólo ella habla latín". Pero la carta antigua tenía ambiciones más grandes. Nacida en un mundo que desconocia los medios masivos de comunicación, la carta alojaba lo mismo al mensaje más ocasional y privado, que a las epístolas más públicas y literarias. La antigüedad vio en el género epistolar, sobre todo, el reflejo del carácter del individuo: "se puede decir que cada uno escribe la carta como retrato de su propia alma", ${ }^{2}$ pero en esos mismos mensajes nosotros creemos percibir otras modalidades de comunicación a través de la voz o el escrito, y otra forma de resolver las urgencias que cada uno resiente por el otro.

'San Jerónimo, Epistolario. Madrid, Biblioteca de Autores Cristianos, 1993, 7, 2.

${ }^{2}$ Demetrio de Falero, Sobre el estilo. Madrid, Gredos, 1979, p. 227. 


\section{La voz y la escritura}

Es notable que la carta antigua tuviera que coexistir en plano de igualdad con el mensaje verbal. Por supuesto la escritura alfabética ya estaba ahi, disponible desde el siglo vin a. C. como tecnología de comunicación, pero debió enfrentar el enorme prestigio que la oralidad y la retórica poseían en la antigüedad. La palabra escrita no recibió de inmediato la confianza colectiva y durante largo tiempo no logró sustituir a la voz viva. Por el contrario, el mundo antiguo siempre consideró al habla persuasiva y bien ejecutada como el rasgo más característico de la vida civilizada, mientras la palabra escrita era más bien un derivado de la retórica. ${ }^{3}$ Se preferia arreglar los asuntos verbalmente, en lo personal o a través de un mensajero confiable.

La carta podía acompañar al mensajero, pero con frecuencia el mensaje hablado era más significativo y en ocasiones era el único mensaje real. El enviado podia tener tanta o mayor importancia que el escrito: se le pedia que transmitiera el mensaje en el momento de su llegada, y pcrduró mucho tiempo la costumbre de interrogarlo en busca de información adicional. Aun la carta más explícita era incapaz de contencrlo todo, por eso san Basilio (siglo IV d. C.) debió explicar a Teófilo que había esperado hasta encontrar un mensajero capaz de informarle lo que hubiese olvidado escribir. ${ }^{4}$ Además, la carta podía ser interceptada y revelaria su contenido sin la mínima resistencia que el más mediocre de los mensajeros podría ofrecer. Y por último, la carta era muda y su silencio podía tener consecuencias desastrosas como le sucedió a Astianacte, tirano de Lámpasco, ${ }^{5}$ quien recibió una carta anunciándole un complot en su contra, pero pospuso su lecrura y fue asesinado con la carta aún en las manos. Sólo gradualmente los méritos de la escritura se impusicron a los privilegios de la voz.

¿Cómo se escribía una carta? La oralidad se hacía presente desde la elaboración de la carta. En efecto, siguiendo los hábitos memorísticos y verbales de composición, las cartas eran generalmente dictadas por sus autores. Múltiples signos lo muestran pero uno explícito se encuentra en una carta del siglo II en la que su autor declara: "mi salud es pobre, pero aún soy capaz de escribir porque mi lengua y mis facultades mentales están intactas".

${ }^{3}$ S. Stowers, Letter Writing in Greco-Roman Antiquity. Filadelfia, The Westminster Press, 1986, p. 101.

${ }^{4} \mathrm{D}$. Gorce, Les voyages, l'hospitalité et le port des lettres dans le monde chrétien des IV et v siecles. Paris, Librairie A. Picard, 1925, p. 215.

'S. Lewis, News and Society in the Greek Polis. Londres, Duckworth, 1996, p. 144.

${ }^{6} \mathrm{E}$. R. Richards, The Secretary in the Letters of Paul. Tübingen, Wissenschaftliche Untersuchungen zum Neven Testament, 1991, p. 19. 
Cicerón, Julio César, san Pablo, Séneca o san Jerónimo seguían ese hábito. Este mundo retórico no veía en el dictado sino ventajas, algunas inesperadas, como cuando Plinio sugiere a otro orador que para mejorar su voz, además de leer en voz alta textos bien escritos, "escribiera" cartas. El dictado permitía a los autores ocuparse de su correspondencia en cualquier momento: Cicerón, por ejemplo, relata varias veces que "escribía" a sus amigos mien. tras se reclinaba para descansar o cenar, y Plinio el Viejo se hacía acompañar en todas sus salidas por su secretario a quien había provisto de unos gruesos guantes, para no ver interrumpido su dictado durante el invierno. Todas las clases sociales recurrían al dictado de cartas: entre los aristócratas el uso del secretario era constante, pero aun las clases bajas, quizá más apegadas a los mensajes verbales cuyo contenido podian controlar, recurrian a escribas en el caso de sus cartas más importantes.

De acuerdo con sus habilidades y el deseo del autor, el secretario tomaba dictado silaba a silaba (syllabatim) o a la velocidad normal del habla (verbatim). Esto último era posible gracias a la taquigrafia antigua, una in vención que según Séneca era atribuible a los esclavos más viles. ${ }^{\top}$ Aunque ello representaba una ventaja desde el punto de vista retórico, cuando el autor deseaba asegurarse de la transcripción literal de sus palabras, dictaba syllabatim, lo que le suponia un mayor consumo de tiempo, pero una mayor precisión. El secretario tomaba notas de lo que el autor dictaba. En algunos casos se limiraba a registrar exactamente las palabras pronunciadas, pero con más frecuencia tomaba apuntes, los cuales expandía y ordenaba poste. riormente. Su papel se acrecentaba entonces actuando como "editor" o coautor de la carta; éste debió haber sido el caso más frecuente, dada la detectable presencia del secretario en las cartas. ${ }^{8}$ Cuando Cicerón se queja. ba de que durante la enfermedad de Tirón no había escrito nada digno de un corresponsal como Pompeyo, no era porque hubiese dejado de escribir o dictar, sino porque sus cartas no habían recibido la atención necesaria como para ser presentadas a un igual.

Al dictar la carta el autor establecía al menos los términos generales. Entregaba la responsabilidad íntegra de la redacción únicamente en el caso de los mensajes más impersonales, como las cartas de invitación o de recomendación. Sin embargo, la carta había adquirido tal importancia como expresión de amistad, que en circunstancias excepcionales era preferible dejar a otro la correspondencia propia antes que romper los lazos que la carta

${ }^{7}$ Séneca, Cartas a Lucilio. México, SEP, 1985, cap. XC, p. 25. Aunque la existencia de la taquigrafia latina está fuera de duda, la existencia de una taquigrafia griega es más dificil de probar.

${ }^{8}$ El secretario de san Pablo, Tercio, se identifica y agrega sus propios saludos a los destinatarios (Biblia, Rom. 16:22). 
aseguraba. Por eso en momentos de profunda depresión, Cicerón pidió a Ático que escribiera cartas en su nombre: "escribe en mi nombre a quien te parezca. Tú conoces a mis amigos íntimos. Si echan de menos mi sello o mi letra, les dices que la he ocultado pues me están vigilando". En todos los casos se esperaba que el autor revisara y corrigiera la versión final y era suya toda la responsabilidad acerca del contenido, estilo y aun la forma de la carta. Ningún destinatario se atrevía a culpar al secretario por aquellas razones que pudieran ofenderlo, lastimarlo o incluso hacerlo dudar de la amistad del autor.

Era exigible al secretario que presentara la carta en forma conveniente. Cuestión relevante porque la carta antigua estaba sujeta a un número considerable de fórmulas estereotipadas. Las misivas debían respetar escrupulosamente esas prescripciones y era usual que el destinatario se quejara ante el remitente de lo impropio de la carta recibida. Se conserva una carta, del siglo il a. C., en la que un oficial debía dirigirse a un puesto jerárquicamente superior que estaba vacante y al cual él estaba siendo promovido; por consiguiente, se escribió una carta a sí mismo en la que incluyó todos los títulos honoríficos que eran requeridos. ${ }^{10}$ Las estrictas fórmulas del mensaje reque. rían pues de la pericia de los secretarios. Aunque esto los obligaba a tener algún tipo de entrenamiento es improbable que ellos recibieran alguna formación especial. El aprendizaje de la escritura de cartas parece haber formado parte de las lecciones dadas por el grammaticus. La prueba es que los grandes autores epistolares son aquellos que habían recibido una cuidadosa formación retōrica. Pero los secretarios no pertenecían a ese grupo. Quizá fueron estas carencias las que impulsaron la elaboración de los primeros manuales prácticos de escritura de cartas atribuidos a Pseudo Demetrio (siglo i a. C.) y a Pseudo Libanio (siglo IV d. C.). En estos manuales no se ofrecía una colección de cartas tipo a imitar, sino una selección del estilo y tono adecuados para cada situación epistolar típica en la que podian encontrarse los corresponsales de las diversas clases sociales. A partir de esos esquemas, el secretario podía modificar siguiendo el ideal que tenía a la vista. La in. fluencia de esos manuales debió ser muy grande, porque la carta antigua fue notablemente conservadora; aunque algunos cambios en la tradición son perceptibles, lo más sorprendente, entre los siglos IV a. C. y IV d. C., son los rasgos epistolares que permanecieron constantes e inalterados.

Ia carta antigua tenía una rigida estructura interna: se iniciaba con ia praescriptio, seguida por el prooemium, luego el contenido y finalmente

'Cicerón, Cartas a Ático. México, uNAM, Instituto de Investigaciones Filológicas, 1976, XI.II.3.

${ }^{10}$ Apud E. R. Richards, op. cit., p. 92. 
la suscriptio. La primera, la praescriptio, estaba formada por el nombre del remitente, el nombre del destinatario y un saludo, en ese orden: Demetrio a Publio, saludos. Ella podia ser embellecida o extendida mediante títulos, dignidades o términos de parentesco. El mundo cristiano y en particular san Pablo impusieron a la praescriptio un sello propio, sustituyendo la antigua forma griega jaire, "alégrate", y al semítico "paz y misericordia", con formas más elaboradas: "gracia y paz a vosotros"," o bien "gracia y paz de dios nuestro padre y señor Jesucristo". ${ }^{2}$

A renglón seguido venía el prooemium que servía para expresar el deseo de que el destinatario estuviera a salvo, bajo la forma de una oración (llamada formula valetudinis), o un voto por su salud, a la que podía agregarse una expresión de gracias a uno o más dioses. Los antiguos romanos usaban la fórmula S.V.B.E.E.V. (si vales bene est, ego valeo), "si estás bien, está bien; yo estoy bien". Nuevamente, el mundo cristiano introdujo modificaciones importantes: san Pablo, además de anticipar brevemente en el proemio el contenido de la carta, solía utilizar fórmulas del tipo: "gracias a dios que...", o incluso una elaboración mayor llamada eulogia: "bendito sea dios... que..."13

La praescriptio y el prooemium no eran un encabezamiento, ni formas puramente convencionales; eran parte de la carta propiamente dicha y podían ocupar un segmento muy importante de ella, sobre todo en las cartas más cotidianas. Por eso mismo ambos se continuaban hacia el contenido sin transición o con un sencillo "y ahora", como en las cartas sumerias. ${ }^{14}$ Desde luego, el contenido de las cartas antiguas es muy variado y dificil de catalogar. No obstante, la manía clasificatoria de la antigüedad buscó distribuir los tipos de cartas de acuerdo con el objetivo que perseguían. Uno de los manuales previamente mencionados, el de Pseudo Demetrio, ofrece una clasificación en 20 especies de carta: amistosa, recomendatoria, censoria, reprobatoria, castigatoria, admonitoria, amenazatoria, vituperatoria. laudatoria, persuasoria, rogatoria, interrogatoria, contestatoria, alegórica, explicatoria, acusatoria, defensoria, congraculatoria, irónica y de agradecimiento. ${ }^{15}$ Pseudo Libanio (siglo iv d. C.) autor de un manual de epistolografia similar, pero con el doble de tipos, incluyó entre sus novedades la carta amatoria y la carta "mixta" que él consideraba la más ingeniosa.

"Biblia, 1Tes. 1:1.

12 Ibid., 1Cor. 16:23.

$13 \mathrm{P}$. Vielhamer, Historia de la literatura cristiana primitiva. Salamanca, Sígueme, 1991, p. 81.

${ }^{14} \mathrm{~J}$. White, "The Ancient Epistolography Group in Retrospect", en Semeia, núm. 22, 1982, p. 10.

${ }^{15}$ He tomado la traducción al castellano de A. Reyes, Literatura epistolar. México, Editorial Jackson, 1966, xv. 
La estructura de la carta antigua estaba fuertemente condicionada por las reglas retóricas que su contenido obedecía. Desde Aristóteles, el género de la retórica estaba dividido en tres especies: a) la especie "judicial" o forense, utilizada por los oradores en las cortes de justicia, cuyas prescripciones dominan en las cartas acusatorias y las cartas apologéticas; $b$ ) las cartas de reprensión o de advertencia seguían la retórica "deliberativa", que los oradores empleaban ante las asambleas públicas para definir cursos de acción adecuados, y c) la mayoría de los tipos epistolares de la antigüedad caben en la tercera especie retórica: la epideíctica o panegírica, utilizada por los rétores en ceremonias específicas para enardecer al público, alabándolo o censurándolo. Su predominio se explica porque esas cartas afectaban las ideas de honor y vergüenza, cruciales en el mundo antiguo. A ellas nos dedicaremos más adelante; por ahora, señalemos que siguen la retórica del elogio aquellas cartas destinadas a la recomendación, la felicitación, el agradecimiento, el consuelo e incluso las cartas eróticas y diplomáticas. Entre las misivas que obedecían a la retórica de la censura estaban las de admonisión, reprensión, reproche, vituperación, reprobación y hasta la carta irónica que, fingiendo alabanza, en realidad contiene una crítica.

Las cartas privadas de la antigüedad eran generalmente breves. Entre las aproximadamente 14000 que se han conservado, el promedio es de $87 \mathrm{pa}$ labras por carta, en un intervalo entre 18 y 219 palabras. A medida que su carácter era más literario y público, tendían a ser mayores: las cartas de Cicerón tienen en promedio 295 palabras; las de Séneca, 995 palabras, y las epístolas de san Pablo, 2495 palabras. ${ }^{16}$ Pero cualquiera que fuese la extensión, una vez terminado el contenido, la carta era concluida con la suscriptio, que era el lugar en que se encontraba la autentificación por parte del remitente y sus saludos al destinatario, y a los parientes próximos de este último. Los romanos usaban el escueto vale, "que tengas salud", equivalente al final griego, erroso, errosthe, "tened salud". Los cristianos tendieron a usar formas más elaboradas buscando expresar su deseo de paz, como "La gracia del señor Jesucristo esté con vosotros". 17

\section{La valoración antigua de la carta}

La carta en papel debió refugiarse en el ámbito íntimo y confidencial a medida que surgieron los medios masivos de comunicación: el libro impreso y los periódicos. En la antigüedad la situación era diferente: la carta debía re-

\footnotetext{
10 E. R. Richards, op. cit., p. 213.

17 Biblia, 1Tes. 5:28.
} 
emplazar a la voz viva del ausente, pero también debía transmitir acontecimientos, difundir opiniones, propagar manifiestos públicos de educación o dirección espiritual. Es en cierto modo inexacta la distinción usual entre cartas personales "auténticas", sin pretensiones literarias por un lado, y por otro, las epístolas que buscan un auditorio ilimitado, que carecen de intimidad y para las cuales la escritura es fundamental, porque la carta antigua era simultáneamente un medio personal de comunicación y un medio de publicación de ideas. En la carta antigua se mezclan elementos que para nosotros están claramente diferenciados, entre lo que pertenece a la confidencia y lo que conviene exhibir ante todos. Esta situación debía naturalmente influir en las diferentes valoraciones atribuidas al mensaje escrito. Veamos más de cerca.

Las primeras cartas históricas conocidas en el mundo griego clásico fueron obra de Polícrates de Samos y del rey Amasis (siglo vIl a. C.). Las cartas debieron ser en ese momento más bien una excepción. Lo muestra una de las primeras cartas de esa época que se conserva, escrita en un pedazo de plomo y que contienc cl mensaje desesperado de alguien que está en pe. ligro de ser convertido en esclavo. Varias cosas son notables: primero, la elección de un mensaje escrito y no verbal para informar, luego el que el remitente no tuviese a la mano ningún material conveniente para cnviarlo y, finalmente, que él no parece conocer ningún nombre específico para "car. ta", porque cuando se refiere al envio mismo, usa el término "plomito". ${ }^{18}$ No fue sino hasta las últimas décadas del siglo v a. C. que se hizo indispensable un nombre especifico para "carta": el término epistolai, que originalmente denotaba "instrucciones", se ocupó de la tarea ${ }^{19}$ Pero ello no propició que las cartas se convirtieran en objeto cotidiano. De hecho, entre los griegos, la carta no logró evitar el estigma de objeto potencialmente deformado y falso. Ese mundo parcialmente alfabetizado siempre vio con suspicacia al mensaje escrito: la carta, que no se dejaba interrogar ni cuestionar, hacía más difícil detectar a la mentira. En su parquedad, ella exigía credibilidad incondicionada e instantánea y por tanto resultaba mucho más poderosa en el engaño que la palabra hablada. Cuando en un anacronismo los trágicos griegos mencionaban la existencia de cartas en la edad heroica, con frecuencia era para precipitar la ruina del bondadoso: así, una carta de Fedra perdió a Hipólito, otra falsedad escrita llevó a la muerte a Palamedes, y fue también una carta de Agamenón la que atrajo a Ifigenia a su sacrificio en Aulide. Incluso, entre los historiadores griegos, la carta era instrumento de falsedad, traición y muerte: ella podía engañar aun al que la transportaba,

${ }^{18}$ W. Harris, Ancient Literacy. Cambridge, Universidad de Harvard, 1989, p. 56.

${ }^{19}$ Ibid., p. 57. 
como esos mensajes que Pausanias enviaba al rey persa que decian algo como: "deberás asesinar al portador de la presente" ${ }^{20}$ En el mundo griego clásico, la carta nunca fue tan confiable como para reemplazar de manera sistemática a la comunicación oral.

A diferencia del mundo griego, entre los latinos las cartas fueron abundantes, y los romanos, aun los más cultivados, eran aficionados a escribirlas. Las cosas habían comenzado a cambiar desde el periodo helenístico, en el que incluso las cartas escritas por mujeres se habian multiplicado. ${ }^{21}$ Aunque los historiadores romanos cometen el anacronismo de mencionar cartas en la primera república e incluso en la monarquía, lo cierto es que no fue sino hasta la época de Plauto (siglo III a. C.) que las cartas se hicieron de uso corriente. ${ }^{22}$ Varias razones concurrían en ello: el tránsito a través de la península se había hecho más seguro, las distancias se recorrian en tiempos más razonables, se disponía de papiro en cantidades apropiadas y se había elevado el nivel general de alfabetización. Los romanos convirtieron a la carta en la fuente principal de información: generales en campaña, senadores, poderosos, todos ellos incluían en sus cartas informes equivalentes a modernos extractos de prensa. Descubrieron, además, que la misiva no servía únicamente para informar, sino también como medio personal de propaganda en el conflictivo mundo político romano.

Quizá la mayor aportación romana fue elevar a la carta a la calidad de género literario. Tradicionalmente, la carta ha sido considerada el menos literario de los géneros escritos; fue mérito de los latinos dignificarla como literatura. ${ }^{23}$ No es fortuito que la primera colección importante de correspondencia privada que poseemos sea la de Cicerón. Plinio el Joven llevó aún más lejos esa valoración de la carta como especie literaria en sentido pro. pio. Y mientras séneca aprovechaba las propiedades de la carta como instrumento de meditación filosófica y de autoeducación, Horacio y Ovidio la convertian en un género hexamétrico, el primero, y en un estilo prosistico, el segundo. Probablemente este aspecto estetizante se explique porque las condiciones políticas del Imperio habian hecho imposible la espontaneidad que se percibe en las cartas de Cicerón; el hecho es que, en Roma, la carta dejó de reflejar las urgencias de la vida cotidiana para expresar el tranquilo distanciamiento de la literatura.

${ }^{20}$ Apud S. Lewis, op. cit., p. 144.

${ }^{21} \mathrm{Cf}$. S. Cole. "Could Greek Women Read and Write?", en H. Foley, ed., Reflections of Women in Antiquity. Nueva York, Gordon and Bisach Publishers, 1981.

${ }^{22}$ G. Achard, La communication a Rome. Paris, Éditions les Belles Lettres, 1991, p. 132.

2. M. von Albrecht, Historia de la literatura romana. Madrid, Editorial Herder, 1997 , p. 484 
Por su parte, el mundo del primer cristianismo otorgó a las cartas un valor excepcional. Había varias razones para ello, pero la más importante era su capacidad para actuar como vehículo de exhortación moral y de difusión pastoral. Es notable que los primeros escritos cristianos que pueden ser datados con relativa seguridad sean las cartas auténticas del apóstol Pablo. ${ }^{24}$ Ellas fueron también los primeros escritos que merecieron ser coleccionados, imitados y hechos circular más allá de sus destinatarios originales. Las epístolas de san Pablo fueron las primeras en ser consideradas textos apostólicos y, finalmente, esas cartas fueron los primeros textos cristianos que recibieron el nombre de Escrituras. ${ }^{25}$

Dos rasgos distinguieron a las cartas cristianas: por un lado, a diferencia de la carta personal, ellas fueron concebidas desde el inicio como públicas. Desde un punto de vista textual están más próximas a ensayos teológicos que a correspondencia ocasional. Adoptan algunas veces el formato de cartas, pero no contienen ninguna pretensión epistolar en sentido usual. Ingresan en la categoria de cartas únicamente porque están escritas en un lenguaje mucho más cotidiano que literario, utilizan los mismos procedimientos retóricos y recurren al mismo medio que las cartas para su difusión: la lectura en voz alta. Las cartas cristianas pertenecen a un género mixto: tienen el tono familiar de las cartas privadas, la autoridad y el objetivo de las cartas oficiales y la función didáctica de la carta filosófica. En segundo lugar, las cartas cristianas ofrecen un clima espiritual particular, compuesto de una mezcla del estilo de exhortación -que desde Epicuro buscaba el adoctrinamiento del lector-y de los valores propios de la amistad cristiana. La amistad había sido una de las grandes motivaciones de las cartas greco-roma. nas, pero el primer cristianismo hizo de la carta algo más que el intercambio de opiniones y confidencias: la convirtió en un verdadero documento espiritual en el que cada alma rivalizaba en dibujarse escrupulosamente y en exteriorizar cada vez más su vida interna. Pero, incluso, documentos tan personales no eran privados y tras ellos se adivina el intento por alcanzar un público cada vez más amplio: la iglesia, la provincia e incluso el mundo entero. Con sus manifiestos espirituales el cristianismo condujo a la carta hasta los bordes de un medio masivo de conversión espiritual.

El cristianismo exhibía con claridad que la carta antigua era también "publicación". Lo era en más de un sentido permitiendo que se multiplicaran

${ }^{24}$ Las epístolas auténticas de san Pablo fueron escritas probablemente en la sexta década del siglo I. Todos los evangelios son posteriores y su datación es más incierta: Marcos (quizá elaborado entre los años 65.70), Mateo y lucas (probablemente entre los años 80-90).

${ }^{25} \mathrm{H}$. Gamble, Books and Readers in the Early Church. Cambridge, Universidad de Yale, 1995, p. 58. 
las palabras del autor. De hecho, además de enviar copias de la carta por diversas vías, el secretario conservaba un ejemplar que servía para reemplazar las eventuales pérdidas, y para probar que la carta había sido efectivamente escrita. Es probable que las recopilaciones antiguas como las de Cicerón, Séneca o san Jerónimo no provengan de cartas reunidas posteriormente, sino de copias retenidas por sus secretarios. Pero al conservar copias de sus cartas los autores solian tener intenciones adicionales: en su deseo de propagar su punto de vista, ellos podian acompañar la carta con misivas enviadas a otros destinatarios. Un caso notable era Cipriano, obispo de Cartago (siglo III d. C.), quien acompañó un mensaje dirigido al clero de Roma con 13 cartas suyas escritas para otras ocasiones, solicitando que todas fueran dadas a conocer. No era excepcional. Los autores solian reutilizar los textos y parece haber sido enteramente aceptable usar el mismo tema o argumento en más de una carta si el destinatario era diferente. Incluso, intercambiaban las cartas que habían escrito; así, Polio escribió a Cicerón: "Le estoy enviando para su lectura cuidadosa una carta que he escrito a Balbo". ${ }^{26}$ Los destinatarios actuaban del mismo modo, compartiendo con amigos la correspondencia recibida, de manera que podían tropezarse con fragmentos ya conocidos: "La carta que me han comunicado contiene el mismo pasaje que usted me escribió a mí, acerca de su hermana" ${ }^{27}$ Las cartas formaban parte de una conversación colectiva; al final resultaba dificil borrar todas sus huellas, por eso, en circunstancias peligrosas, Cicerón debió pedir a sus corresponsales que destruyeran las diversas copias existentes.

Estc intercambio incesante no representaba ninguna pérdida de privacía. Normalmente las cartas eran dictadas a los secretarios en presencia de muchas personas. Cuando la carta era recibida, el destinatario solía preferir que fuese leída en voz alta por su lector, especialmente si había amigos presentes, que asi tenian conocimiento de información útil para todos. La voz era la primera forma de "publicación" de la carta antigua, previa a su reproducción escrita. Las mismas epístolas de san Pablo fueron "publicadas" por vez primera en el momento en que fueron recibidas y leidas en voz alta ante la comunidad reunida, quizá en el momento ceremonial en el que se intercambiaban los saludos y el "beso sagrado" al que san Pablo se refiere en algunas cartas. ${ }^{28}$ La lectura en voz alta estaba a cargo de un lector especializado, el anagnostes, tan útil que aun cuando un autor antiguo escribe algo como "he leído tu carta", eso no implicaba que no hubiera recurrido al lector. La vejez aportaba un argumento adicional porque la ausencia de ante-

\footnotetext{
${ }^{26}$ Cicerón, Letters to his Friends. Cambridge, Loeb Classical Library, 10.32.5.

${ }^{27}$ Cicerón, apud E. R. Richards, op. cit., p. 5.

${ }^{28}$ Biblia, Rom. 16:1; 1Cor. 16:10, y Ef. 6:21.
} 
ojos, desconocidos en la antigüedad, hacía prácticamente obligatoria la lectura en voz alta por el anagnostes.

Después de la lectura en voz alta, la copia era la otra forma de "publicación" de la carta. La antigüedad hizo de la copia una actividad apreciada. Cicerón, por ejemplo, aprovechaba algunas reuniones en su casa para hacer leer a los invitados las cartas que escribía o que recibía; si alguno de ellos disfrutaba especialmente alguna carta, le bastaba solicitar una copia. Autores como Cipriano pedían explícitamente que se dieran todas las facilidades a aquellos que deseaban copiar sus cartas. No todos usaban estos medios lícitos: Lépido, por ejemplo, era conocido por interceptar, leer e incluso destruir mensajes ajenos. No estaba solo en ese vicio, ya que al mismo Cicerón le ocurrió ocasionalmente mandar interceptar algunas cartas.

El carácter público de la carta antigua produjo diversas actitudes hacia su autoría. Un ejemplo notable fue la elaboración de cartas espurias, que llegaron a convertirse en un género particularmente importante; las había "pseudónimas" o "heterónomas", es decir, que fingían el estilo de algún autor célebre al que mencionaban por su nombre. Las cartas griegas atribuidas a Platón, Aristóteles y Demóstenes, por ejemplo, son casi todas ellas falsas, con la posible excepción de la carta número siete asignada a Platón. En algunos casos se trata de falsificaciones reales, provenientes sobre todo de los dos últimos siglos previos a la era cristiana, quizá debido a la avidez de las bibliotecas entonces nacientes. Pero en muchos otros casos se trataba de ejercicios escolares 0 invenciones que la antigüedad no consideraba falsificaciones sino una especie de homenaje biográfico, expositivo o instructivo, rendido a esos grandes hombres.

Una especie de la antigüedad:

las cartas paraenéticas de exhortación

Como es natural, en las cartas antiguas están presentes los vínculos afectivos o jerárquicos de la sociedad que las produjo. Desde luego, esos vínculos son diversos y no es posible aquí examinarlos todos, por eso hemos elegido una especie que resulta característica de la antigüedad: las cartas paraenéticas. Paraenesis es una palabra griega que usualmente se traduce como "exhortación". En una carta paraenética se expresa entonces un exhorto bajo la forma de una serie de preceptos de sabiduría, especialmente de naturaleza moral. Desde el punto de vista retórico esas cartas pueden pertenecer a la especie "epideíctica" o incluso "deliberativa". Su ubicación resulta incierta porque la exhortación no fue un tema retórico sino filosófico, vinculado a la ética. De ahí proviene su larga tradición que tiene su origen en la concepción anti- 
gua de la filosofia y que encontró un desarrollo natural en los objetivos del primer cristianismo. En efecto, cualesquiera que fuesen sus objetivos epistemológicos o metafisicos, la filosofia antigua incluyó entre sus propósitos básicos promover una vida virtuosa y feliz. Desde esta perspectiva, la filosofia era menos un sistema que un ejercicio preparatorio a la sabiduría. ${ }^{29}$ Su figura paradigmática, Sócrates, no escribió un solo libro, pero dejó lecciones imperecederas en su manera de vivir y de morir. Después de Sócrates, un gran número de filósofos se dedicó al cuidado del alma, de la suya y de la de los demás, para hacerlos tan buenos como fuera posible. Ellos sabían que en la preparación de un discípulo, normalmente había un momento de profunda conversión moral. Pero no importa qué tan dramática fuese, esa conversión era insuficiente y el aspirante a filósofo requería de una orientación larga y continua, la cual, en ausencia de la voz viva del director espiritual, sólo podía ser asegurada por las cartas. Aquí encuentra su razón de ser la abundante producción de cartas paraenéticas.

Las cartas se prestaban a la perfección, porque en ellas se expresaba de inmediato el carácter del autor. Adoptaban un tono exhortatorio porque su propósito era afectar los hábitos y la disposición moral del lector, de acuerdo a un cierto modelo de vida considerado intrínsecamente valioso. Las cartas tenían la calidez de un consejo verbal, por eso, aunque podían seguir un estilo argumentativo, preferían ofrecer modelos vivos de conducta que debían servir al discípulo como guías. A Igunas veces la exhortación sugería cambiar radicalmente un modo de vida considerado erróneo: era la llamada carta protréptica: "Lo que te pido con el mayor encarecimiento es que tú, aunque lo de fuera te vaya bien, mires hacia lo de dentro: que el cambio de felicidad por bienestar es el de oro por bronce". ${ }^{30}$ En otros casos la carta exhortaba, mediante preceptos de carácter tradicional o confirmatorio, a mantener un modo de vida ya adoptado; era la paraenesis propiamente dicha:

Sé que es evidente para ti Lucilio que nadie puede llevar una vida feliz, ni tolerable siquiera, sin la afición de la sabiduría, y que es la sabiduría perfecta la que hace feliz la vida. Pero esto que es claro, hay que confirmarlo y arraigarlo más profundamente con la meditación cotidiana; mayor trabajo es cumplir los propósitos que concebirlos. ${ }^{31}$

Aquel que enviaba la carta era igual o moralmente superior al destinatario. Había entre ambos un componente de amistad que justificaba el exhor-

\footnotetext{
29 P. Hadot, Qu'est-ce que la philosophie antique? Paris, Gallimard, 1995, p. 47.

3o Sinesio de Cirene, Cartas. Madrid, Gredos, $\mathrm{Cl}$.

"Séneca, op. cit., XVI.1
} 
to, porque según la concepción antigua era un deber de amistad prestar atención al desarrollo del carácter de cada uno. Este tipo de carta era entonces más común en la amistad de los más altamente educados: escritores o filósofos. El amigo podía exhortar pero también le era permitido advertir o corregir; eso era lo que según los antiguos lo distinguía de un simple adulador. La carta paraenética podía así contener admoniciones y en muchos casos resulta dificil distinguirla de una carta de amonestación: "He oído Lysis que has estado constantemente borracho desde el concurso en Eretria. Si esto es verdad, te corresponde no ver con desprecio lo que Homero el sabio dice: 'el vino destruyó incluso a un centauro, el notable Eurytion', y también al Cíclope a pesar de su talla y su fuerza sobrehumanas". ${ }^{32}$

La carta exhortatoria no era un simple enlistado de preceptos o virtudes. En ella había un patrón implícito de principios incuestionables de conducta que habían sido sancionados por el honor y la vergüenza, valores básicos de la cultura aristocrática antigua. Para promover esos patrones, los autores tenían a su disposición una serie de ejemplos históricos o legendarios, pero con mucha frecuencia preferían ofrecer su propia conducta como modelo a imitar: "Tú tienes un modelo ante ti, sobre cuyas huellas puedes caminar, y eres verdaderamente afortunado para gozar de un ejemplo vivo que es a la vez el mejor posible y tu pariente cercano, en breve, para tener como ejemplo a imitar a aquél a cuya naturaleza deseas aproximarte". ${ }^{33}$ La tradición de la carta exhortatoria puede remontarse hasta Epicuro, pero la colección más importante que poseemos son las cartas que Séneca dirigió a Lucilio.

Por su naturaleza pastoral, la carta paraenética ocupó un lugar privilegia. do en el primer cristianismo, comenzando por las epístolas de san Pablo. Sus elementos básicos son preceptos, ejemplos, discusiones de tópicos morales tradicionales, advertencias memoristicas de lo ya logrado y razones para continuar con la conducta adoptada. Las cartas exhortatorias van desde simples sermones de misionero hasta tratados teológico-filosóficos de la talla del Protréptico de Clemente de Alejandría. En ellas, los cristianos tampoco excluían sentencias de admonición porque estaban convencidos que la paraenesis no era un simple discurso adulatorio. La admonición era una forma de condena, pero los moralistas consideraban que era susceptible de producir metanoia, es decir, un cambio de mentalidad mediante la vergüen$\mathrm{za}$, aunque fuese una vergüenza atenuada. La carta podía tener adicionalmente un componente didáctico, porque los moralistas pensaban que con frecuencia la conducta impropia era debida a creencias erróneas.

${ }^{32}$ Carta de Crates a Lysis, siglo II d. C., apud S. Strowers, op. cit., p. 29.

33 Plinio el Joven, Letters and Panegyricus. Cambridge, Loed Classical Library, VIII.13. 
Las formas más suaves de admonición estaban aún emparentadas con el habla exhortatoria, pero a medida que la censura se acentuaba, la paraenesis cedía su lugar en las cartas a la reprensión y al reproche. Las cartas de reprensión hacían de la vergüenza el argumento esencial para la corrección de las deficiencias de carácter ocultas en la conducta inmoral. Se trataba en los hechos de una terapéutica, una remodelación de los impulsos mediante aflicciones severas, puesto que, según Plutarco, el arrepentimiento era una clase de dolor y la vergüenza una clase de miedo. A diferencia de la amorosa y gentil admonición, la reprensión era brusca y violenta; aquélla busca corregir las debilidades del individuo, ésta sólo quiere censurarlas: "¿Esperas consuelo? Pues has de recibir una reprimenda. Soportas sin entereza la muerte de tu hijo, ¿qué harias si hubieses perdido un amigo? Falleció un hijo de esperanza incierta, aún párvulo; poco tiempo se perdió". ${ }^{34}$ Estas cartas reprensivas descansaban en la áspera afirmación de los moralistas de que sólo la amputación y la cauterización del oprobio podían curar los vicios más tenaces. Finalmente, el último lugar en la cadena del exhorto a la censura lo ocupaba la carta de reproche, que contenía una condena tan brutal que sólo los filósofos más austeros llegaron a creer que podía producir resultados benéficos. La carta de reproche conducía al límite extremo de la deshonra; en ella se acumulaban duras críticas al carácter del destinatario y con frecuencia incluian la sorpresa del remitente por haber descubierto ese aspecto moralmente despreciable:

Usted ha recibido muchos favores de nosotros y estoy completamente sorprendido de que no sólo no recuerde ninguno de ellos, sino que hable malignamente de nosotros. Esto es propio de una persona que posee una desgraciada disposición. Porque los desagradecidos olvidan a los hombres nobles y por añadidura maltratan a sus benefactores como si fueran enemigos. ${ }^{35}$

\section{El envío de la carta}

Una vez concluido el contenido, el autor debía considerar la autentificación del mensaje. Era un problema de importancia en la antigüedad. La inseguridad del viaje, su posible falsificación, la intervención del dictado que impedía escribir de propia mano, todo eso hacía indispensable alguna garantía para el escrito. Para ello, el autor solía escribir por sí mismo las últimas lí-

${ }^{34}$ Séneca, op. cit., $\mathrm{xcrx}, 2$

${ }^{35}$ Pseudo Libanio, "Epistolimaioi Characteres", en A. J. Malherbe, Ancient Epistolary Theorist. Atlanta, Scholar Press, 1988, p. 77. 
neas de la carta, agregando una salutación afectuosa, la suscriptio y ocasionalmente la fecha y el lugar, que aparecían al final y no al inicio, como entre nosotros. Estas últimas líneas podían adoptar dos fórmas: $a$ ) el sumario, una especie de resumen breve, muy usual en los escritos comerciales para sellar el compromiso, seguido del nombre del escriba en una llamada "fórmula analfabética" en el caso de que el autor desconociera las letras o "escribiera lentamente", como se decía entonces: "yo escribí para Kasios la mayor parte y luego, él escribió lentamente más abajo". ${ }^{36}$ b) La segunda forma de autentificación consistía en agregar material adicional que algunas veces era la parte confidencial o secreta de la carta. ${ }^{37} \mathrm{El}$ autor solia advertir que había tomado la pluma para justificar el cambio de estilo en la escritura. San $\mathrm{Pa}$ blo, por ejemplo, usaba fórmulas como: "el saludo es de mi propia mano, "38 pero en Gálatas señala: "mirad cuán grandes letras os he escrito de mi mano ${ }^{\prime \prime}{ }^{39}$ quizá porque la diferencia era muy marcada con la probable letra pequeña de su secretario.

La ausencia de esas líneas adicionales ponía seriamente en cuestión la autenticidad de la carta, aunque se daba el caso de que se la considerara legítima si los pensamientos que contenía concordaban con las ideas conocidas de su presunto autor. La búsqueda de autentificación no concluía ahí: una vez terminada, la carta era doblada repetidas veces hasta formar una larga tira, la cual era nuevamente doblada en el otro sentido y atada con una cuerda o cinta de papiro. El nudo era sellado con cera caliente sobre la que se imprimía el sello personal, usualmente portado en un anillo, el anulus signatorium si el remitente era un personaje relevante. Ésta era una garan. tía formal tan importante que el término "signare" se refería a "sellar", no a "firmar", porque la antigüedad desconoció la firma como signo manuscrito individual.

Atada y sellada, la carta iniciaba la riesgosa etapa del envío. Nunca hubo, ni en Grecia, ni en Roma, un sistema postal organizado para la correspondencia privada. No fue sino hasta la época de Augusto que los romanos organizaron, con fines militares y diplomáticos, un sistema de estaciones de relevo que suministraba caballos y carruajes para el transporte de cartas y personas en viajes urgentes. Esta correspondencia era llevada por mensajeros imperiales o por soldados de confianza. Sin embargo, su utilización estaba sumamente restringida, al grado que la penúltima carta que Plinio envió a

"N. C. Youtie, "Bradeos Graphon: Between Literacy and Illiteracy", en Greek, Roman and Byzantine Studies, núm. 12, 1971, p. 247.

37 "Aquí vuelvo a escribir de mi puño y letra pues lo que sigue es bastante confidencial" (Cicerón, Cartas a Ático, XI, 24.2).

${ }^{18}$ Biblia, 2Tes. 3:17.

39 Ibid., Ga. 6:11. 
Trajano era para ofrecer explicaciones y pedir disculpas por haber enviado a casa a su mujer, sin haber obtenido autorización previa, para atender la inesperada muerte del abuelo de ésta. Cada uno debía encontrar solución al envío de su correspondencia. Los romanos más adinerados contaban con esclavos especializados en el transporte de cartas, los tabellarii, llamados así según san Jerónimo porque originalmente transportaban tablillas enceradas o pulidas, o simples trozos de corteza de árbol. Solían viajar a caballo, pero también existian los cursores, corredores de Lugurcia especialmente aptos para las grandes distancias. Los corresponsales cristianos recurrían a las instancias menores de la jerarquía eclesiástica: lectores, diáconos, subdiáconos. Las cartas del común de los individuos debian aprovechar a los viajeros ocasionales.

El mensajero recibía una carta que en su exterior indicaba simplemente los nombres del remitente y del destinatario: "De Ausonio a su hermano Ireneo", a veces en imperativo: "Entrega a Máximo de parte de su hermano Sempronio". No era preciso nada más; las indicaciones de la calle y la casa le serían dadas verbalmente. El tabellarius era una cuestión importante, por eso Juan Crisóstomo se vio obligado a escribir que "su lengua estaba encadenada, por falta de mensajeros". ${ }^{\circ 0}$ Cuando el mensaje era verbal, el tabellarius debía poseer las habilidades de retención y de memoria; cuando el mensaje era confidencial debía merecer la confianza que se le depositaba. En efecto, no era infrecuente la indolencia en el viaje y en la entrega, y tampoco lo era la indiscreción. Había mensajeros que en el trayecto, sin ningún pudor, leían las cartas que les eran confiadas. De ahi que para ciertas cartas la confidencialidad llegara a convertirse en un arte: Julio César se habia hecho un experto en el criptograma, Eneas el Táctico aconsejaba ocultar la carta al mensajero cosićndola en las suelas de sus sandalias previamente preparadas, y Ausonio sugirió a san Paulino que escribiera sus cartas con leche, la cual, una vez seca se haría invisible en el papel y no podría ser reanimada sino con ceniza caliente.

Naturalmente, los mensajeros confiables eran muy apreciados. Cuando el enviado no era un simple empleado, era usual anotar al final de la carta que era digno de toda confianza y que merecia cualquier tipo de ayuda que el destinatario pudiera prestarle. Esto se explica porque, excepto en el caso de los esclavos especializados, la carta raramente era el motivo principal del viaje. Esos viajeros eran normalmente cercanos a los corresponsales y solían hacer énfasis en esa intimidad como una forma de obtener atenciones y beneficios. Pero sin excepción, profesionales o de buena voluntad, era dificil retener a esos mensajeros largo tiempo: ellos siempre estaban de prisa, im-

40 Juan Crisóstomo, Epístolas. Madrid, Editorial Juventud, 1957, cxxvin. 
pulsados por aprovechar cualquier circunstancia favorable, el buen tiempo, un barco disponible, para iniciar su retorno. Una gran cantidad de cartas antiguas parecen haber sido escritas sin contenido preciso, simplemente para aprovechar la partida de un viajero, y muchas otras mencionan el apremio que el mensajero imponía al corresponsal. El mismo Cicerón, tan poderoso, se quejaba de esos tabellarii que llegaban a su casa "con sus grandes sombreros de viaje ya puestos, diciendo que sus camaradas los esperaban en la puerta". ${ }^{41}$

Los mensajeros viajaban, sobre todo, en la época de buen clima. Por eso se les encuentra a veces detenidos durante todo el invierno, lo que podía significar que harian únicamente un viaje al año. Aun en estas circunstancias desfavorables, la carta podía viajar a una velocidad razonable, sobre todo, en las distancias pequeñas: una carta entre Roma y Nápoles podía hacer el recorrido en cinco dias. Las cosas eran diferentes en las grandes distancias y sobre todo cuando el mar estaba de por medio: un viaje entre Atenas y Roma, que normalmente requería tres semanas podía durar dos meses. La velocidad de la carta en la antigüedad dependía de las condiciones generales del viaje: un viajero podía normalmente lograr $60 \mathrm{~km}$ por día, aunque eran capaces de proezas como los $140 \mathrm{~km}$ diarios que alguna vez logró Julio César. ${ }^{42}$ Había un flujo normal de viajeros en las grandes rutas romanas, pero había provincias en las que la correspondencia era recibida tres veces por año y regiones en las que ningún viajero deseaba aventurarse. Ésta era la situación en Cucusa, Armenia, donde Juan Crisóstomo esperaba inútilmente recibir de sus amigos una lluvia de cartas.

Ninguna de estas peripecias impidió, sin embargo, que la carta colaborara con el mensaje verbal en el flujo incesante e ininterrumpido de información que la sociedad antigua debió mantener. No fueron pocos los momentos en los que tuvo que competir con la voz viva. La presencia de este conflicto prueba algo que hemos olvidado: en ese mundo retórico la carta representaba un pequeño milagro inesperado. Por un largo periodo ella impuso sus condiciones: a diferencia de los mensajes verbales que se desvanecieron para siempre, algunas cartas permanecieron dejándonos atisbar los signos de amistad, exhortación, reproche o consuelo propios de esa comunidad espiritual. Pero aún durable, esa victoria se revelaría temporal: con el tiempo, la carta personal se convertiria en el medio exclusivo para comunicar confidencias, pero llegaría el momento en que, como hoy, habría de ser desplazada por otros medios en la comunicación de nuestros afectos.

${ }^{41}$ Apud D. Gorce, op. cit., p. 227.

L. Cason, Travel in the Ancient World. Baltimore, Universidad Johns Hopkins, p. 221. 